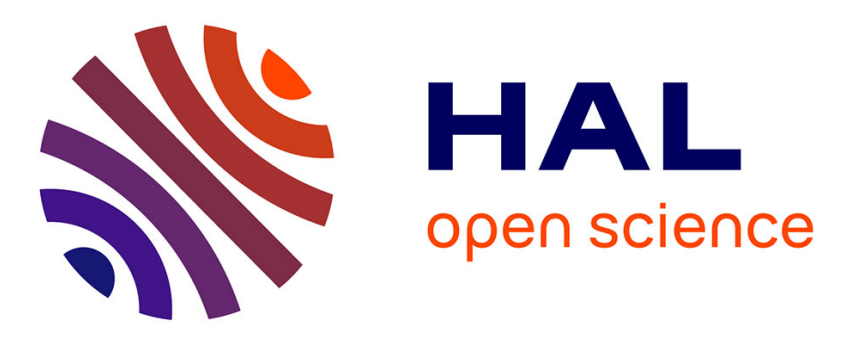

\title{
Identification of moisture diffusion parameters in organic matrix composites
}

Hossein Ramezani Dana, Annick Perronnet, Sylvain Fréour, Pascal Casari, Frédéric Jacquemin

\section{- To cite this version:}

Hossein Ramezani Dana, Annick Perronnet, Sylvain Fréour, Pascal Casari, Frédéric Jacquemin. Identification of moisture diffusion parameters in organic matrix composites. Journal of Composite Materials, 2013, 47 (9), pp.1081-1092. 10.1177/0021998313477963 . hal-01006939

\section{HAL Id: hal-01006939 \\ https://hal.science/hal-01006939}

Submitted on 10 Feb 2018

HAL is a multi-disciplinary open access archive for the deposit and dissemination of scientific research documents, whether they are published or not. The documents may come from teaching and research institutions in France or abroad, or from public or private research centers.
L'archive ouverte pluridisciplinaire HAL, est destinée au dépôt et à la diffusion de documents scientifiques de niveau recherche, publiés ou non, émanant des établissements d'enseignement et de recherche français ou étrangers, des laboratoires publics ou privés. 


\title{
Identification of moisture diffusion parameters in organic matrix composites
}

\author{
Hossein Ramezani Dana, Annick Perronnet, Sylvain \\ Fréour, Pascal Casari and Frédéric Jacquemin
}

In this work, moisture penetration in glass fiber-reinforced polymers was systematically investigated through both experiments and theoretical approaches. The diffusivities of the neat resin and those of unidirectional composite plates containing various glass fiber volume fractions have been identified through the analysis of hygro-thermal aging tests. The main aim of the present paper consists in comparing the evolutions, as a function of the fiber volume fractions, of the moisture diffusion coefficients deduced from experiments to the corresponding values, predicted by the many traditional scale transition relations available in the literature.

Keywords: Composites, diffusion coefficients, identification, scale transition modeling

\section{Introduction}

Fiber-reinforced organic matrix composites are being increasingly used for, as an example, aircraft, ${ }^{1}$ marine $^{2}$ and civil engineering ${ }^{3}$ structural applications. Such composite structures are often submitted to humid environments during their service life., ${ }^{4,5}$ Organic matrix composites do absorb significant amount of water when exposed to moisture. ${ }^{6}$ Many authors have reported that hygro-thermal aging could induce both mechanical stiffness and/or strength reduction of organic matrix composites. ${ }^{7-10}$ Moreover, the constituents of composites structures exhibit heterogeneous coefficients of moisture expansion and maximum moisture absorption capacity. Consequently, multiscale in-depth mechanical states profiles rise during the hygroscopic loading of organic matrix composites. According to the literature, the resulting mechanical states can eventually induce damage. ${ }^{11-13}$ Therefore, analytical models enabling to predict the multi-scale mechanical states occurring during both the transient stage and the permanent regime of the moisture diffusion process of organic matrix composites submitted to hygro-mechanical loads ${ }^{14-17}$ have been developed. In this field of research, the most recent investigations ${ }^{18-22}$ focus upon taking, in theoretical approaches, various features of hygro-mechanical couplings observed during experimental studies into account, especially the dependence of both the moisture diffusion coefficient and the maximum moisture absorption capacity on the mechanical states (strains and stresses). ${ }^{23-27}$ These models aim eventually to enable the prediction of the long-term durability of composite structures submitted to hygroscopic loads.

In order to accurately model the multi-scale mechanical states of a composite structure under hygroscopic environments through one of the above-listed theoretical approach, it is also necessary to predict the time-dependent penetration of moisture in the studied specimen. This often requires to know the macroscopic moisture diffusion coefficients. The identification of the corresponding materials properties is rather lengthy, thus, many scientists tried to circumvent this

Institut de Recherche en Génie Civil et Mécanique (UMR CNRS 6I83), LUNAM Université-Université de Nantes-Centrale Nantes, SaintNazaire cedex, France

\section{Corresponding author:}

Hossein Ramezani Dana, Institut de Recherche en Génie Civil et Mécanique (UMR CNRS 6183), LUNAM Université-Université de Nantes - Centrale Nantes, CRTT, 37 Boulevard de I'Université, BP 406, 44602 Saint-Nazaire cedex, France.

Email: Hossein.Ramezani-Dana@univ-nantes.fr 
problem through the development of dedicated scaletransition models providing adequate homogenization relations between the effective macroscopic coefficients of diffusion and their microscopic counterparts. According to the literature, the authors agree about the scale transition relation that should be applied in order to realistically estimate, by comparison with experimental data, the effective moisture diffusion coefficient in the direction parallel to the reinforcement axis in the case that uni-directional fiber-reinforced polymer matrix composites are considered. ${ }^{28}$ Regarding the identification of the effective moisture diffusion coefficients of a composite ply in the direction perpendicular to the reinforcement axis, the problem is very different. For example, a wide variety of homogenization laws can be found about it: the Shen and Springer model, ${ }^{29}$ the analogy to the electrical conductibility expression, established by Rayleigh, ${ }^{30}$ and the analogy between diffusivities and the effective shear modulus expression from Shirel and Halpin, ${ }^{31}$ as examples. Other methods have been proposed: purely numerical approaches, involving the finite differences methodachieved by Augl and Berger ${ }^{32}$ leading to consistent predictions with Rayleigh model. Another electrical analogy was investigated by Woo and Piggott ${ }^{33}$ : the authors considered the diffusivity as the analogous of the inverse of electrical resistivity. One of the principal interests of this paper is assessing the effects of an added interphase with specific properties between the organic matrix and reinforcing fibers. Subsequently to most of the initial work in this field, Kondo and Taki ${ }^{34}$ corrected an erroneous fundamental hypothesis considered by their predecessors. Despite this, the application of the various, above-mentioned, numerical models, dedicated to the identification of moisture diffusion coefficients in the direction perpendicular to the reinforcing fibers in organic matrix composites, provides scattered values depending heavily on the considered scale transition model.

The present work aims to check the agreement between the predictions of any of the above described scale transition models and the real (i.e. measured) effective diffusive transverse behaviour of unidirectional composites. In order to reach this goal, several glass-fiber-reinforced polymer composites as well as neat resin specimens were manufactured by wet layup, so that their fiber volume fractions would scale in the range 40 to $70 \%$ (see experimental investigation section below). The third section of the present paper describes the results of the aging tests performed on the samples, in order to identify their diffusive behaviour. In the fourth part, the transverse coefficients of moisture diffusion of the manufactured samples deduced from the experiments were compared with the corresponding values calculated through various scale transition relations.

\section{Experimental investigation}

\section{Samples preparation}

The tested unidirectional composite samples were made of E-glass fibers embedded in an ortho-phtalic polyester resin (POLYLITE 420-731 from REICHOLD) polymerizing at room temperature. The specimens were manufactured through a classical contact molding method. Several neat resin samples and composite plates, containing different reinforcing fibers volume fraction $\left(v_{\mathrm{f}}\right)$, between 0.4 and 0.6 , have been produced. The thickness and width of the samples are, respectively, $6 \mathrm{~mm}$ and $23 \mathrm{~mm}$. The length of the samples is equal to $180 \mathrm{~mm}$. As a consequence, the considered length-to-thickness ratio is relatively high $(30: 1)$. The length corresponds to the direction parallel to the reinforcement axis.

\section{Characterization of the fiber volume fractions of a manufactured sample}

Prior studies have demonstrated the significant dependence of moisture diffusion on fiber volume fractions in composites structures. ${ }^{34,33}$ Therefore, this parameter has also a strong effect on the numerical application of the scale transition models employed for predicting the effective transverse diffusion coefficient of such materials. As a consequence, the accurate determination of the glass fibers volume fraction in each investigated sample was mandatory in the context of the present work.

Several techniques are traditionally employed in order to determine the fiber volume fraction $v_{\mathrm{f}}$ of composites. Among them, image analysis, thickness measurement, resin burn off and acid digestion are the most often used for achieving such a task. ${ }^{35-37}$ Other less traditional characterization methods do nevertheless exist for determining the respective volume fractions occupied by the very constituents of an organic matrix composite. As an example, X-Ray diffraction analysis was successfully used as a non-destructive technique. ${ }^{38}$

In the following of the present section, three methods will be used to identify the glass-fiber volume fraction in the manufactured samples.

Determination of the fiber volume fraction from dimension and weight analysis. Optical microscopy and scanning electron microscopy (SEM) were used for investigating the microstructure of the manufactured samples. According to both characterization methods, specimens are void-free. As a result, the total volume of the composite $\left(V_{\mathrm{t}}\right)$ is equal to the sum of the volumes occupied by the glass fibers $\left(V_{\mathrm{f}}\right)$, and by the resin $\left(V_{\mathrm{r}}\right)$ :

$$
V_{\mathrm{t}}=V_{\mathrm{f}}+V_{\mathrm{r}}
$$


A similar relation is also valid for the corresponding masses:

$$
M_{\mathrm{t}}=M_{\mathrm{f}}+M_{\mathrm{r}}=\rho_{\mathrm{f}} V_{\mathrm{f}}+\rho_{\mathrm{r}} V_{\mathrm{r}}=\rho_{\mathrm{t}} V_{\mathrm{t}}
$$

where, the symbol $\rho$ denotes mass densities.

The glass fiber volume fraction satisfies:

$$
v_{\mathrm{f}}=\frac{V_{\mathrm{f}}}{V_{\mathrm{t}}}=1-v_{\mathrm{r}}=1-\frac{V_{\mathrm{r}}}{V_{\mathrm{t}}}
$$

Considering equations (2) and (3) enables to write:

$$
v_{\mathrm{f}}=\frac{\rho_{\mathrm{t}}-\rho_{\mathrm{r}}}{\rho_{\mathrm{f}}-\rho_{\mathrm{r}}}
$$

Dimensions and mass of the specimens were measured in order to determine their total volume $\left(V_{\mathrm{t}}\right)$ and their total mass $\left(M_{\mathrm{t}}\right)$, from which the total mass density calculation is straightforward. The same method was applied to the neat resin samples, so that the numerical value of $\rho_{\mathrm{r}}$ could be deduced. Glass fibers mass density is well-known and available in the literature. ${ }^{39}$ The obtained results, from relation (4) through this calculation method, for the glass fibers volume fraction, are displayed in Table 2.

Determination of the glass fibers volume fraction from image analysis method. The volume fractions of glass fibers can also be determined by studying the samples microstructure through image analysis methods. ${ }^{40}$

Thirty SEM micrographs covering the whole surface of sample section were taken. As shown on Figures 1 and 2, a high contrast between the fibers and the resin was obtained. This enabled to separate the fibers from the remaining material and to calculate the number of pixels associated to fibers on an SEM micrograph. This task was achieved with the aid of the Optimas 6.51 software package. Microscopic work was carried out on a CARL ZEISS-EVO40 SEM using the backscatter electron detector and an operating voltage of $15 \mathrm{kV}$. The results of this analysis are indicated by the acronym I.A. in Table 2 . The information corresponding to the specimen $\mathrm{N}^{\circ} 8$ is not available, since it was damaged during preparation. The results obtained by this method are in good agreement with those obtained by the dimension and weight analysis (D.W.A) method.

Fiber volume fraction determination from inverse method identification. According to Ref. [41], the effective macroscopic maximum moisture absorption capacity of composite materials reinforced by impermeable fibers $M_{\infty}$ depends on both the corresponding properties of

\begin{tabular}{|c|c|c|}
\hline Method & $\begin{array}{l}\text { Equation or } \\
\text { tool used }\end{array}$ & Comment \\
\hline \multirow[t]{2}{*}{ D.W.A. } & $v_{f}=\frac{\rho_{t}-\rho_{r}}{\rho_{f}-\rho_{r}}$ & $\begin{array}{l}\text { (I) Based on the measurement } \\
\text { of the dimensions and mass } \\
\text { of the specimens }\end{array}$ \\
\hline & & $\begin{array}{l}\text { (2) The specimens are assumed } \\
\text { void-free }\end{array}$ \\
\hline \multirow[t]{2}{*}{ I.A. } & $\begin{array}{l}\text { Optimas } 6.5 \\
\text { Software }\end{array}$ & $\begin{array}{l}\text { (I) Based on samples micro- } \\
\text { structure analysis (SEM) }\end{array}$ \\
\hline & $M$ & $\begin{array}{l}\text { (2) Enables to determine the } \\
\text { volume fractions of glass } \\
\text { fibers, resin and porosity }\end{array}$ \\
\hline \multirow[t]{2}{*}{ I.M. } & $v_{\mathrm{f}}=\mathrm{I}-\frac{\rho_{\mathrm{t}}}{\rho_{\mathrm{r}}} \frac{M_{\infty}}{M_{\infty \mathrm{r}}}$ & $\begin{array}{l}\text { (I) Based on Loos and Springer } 4 \\
\text { relation regarding the max- } \\
\text { imum moisture absorption } \\
\text { capacity of composite rein- } \\
\text { forced by impermeable fibers }\end{array}$ \\
\hline & & $\begin{array}{l}\text { (2) The specimens are consid- } \\
\text { ered as void-free }\end{array}$ \\
\hline
\end{tabular}

Table I. Determination of the fiber volume fractions of a manufactured sample.

Table 2. Identified values for the fiber volume fractions of the manufactured samples, obtained according to the three methods considered in the present work.

\begin{tabular}{llll}
\hline $\begin{array}{l}\mathrm{N}^{\circ} \text { of } \\
\text { specimen }\end{array}$ & D.W.A. $v_{\mathrm{f}}(\%)$ & I.A. $v_{\mathrm{f}}(\%)$ & I.M. $v_{\mathrm{f}}(\%)$ \\
\hline $\mathrm{I}$ & $40.2 \pm 1.9$ & $41.6 \pm 1.7$ & $43.4 \pm 1.5$ \\
2 & $39.3 \pm 1.6$ & $40.6 \pm 1.4$ & $39.3 \pm 1.5$ \\
3 & $38.5 \pm 1.8$ & $40.1 \pm 1.9$ & $46.7 \pm 0.8$ \\
4 & $44.0 \pm 2.4$ & $45.2 \pm 1.3$ & $44.9 \pm 1.5$ \\
5 & $46.9 \pm 2.7$ & $47.2 \pm 1.5$ & $43.9 \pm 2.9$ \\
6 & $47.6 \pm 2.3$ & $49.2 \pm 1.2$ & $50.9 \pm 1.7$ \\
7 & $53.4 \pm 2.0$ & $52.8 \pm 1.4$ & $55.9 \pm 1.8$ \\
8 & $51.8 \pm 2.5$ & & $53.4 \pm 3.4$ \\
9 & $55.6 \pm 2.0$ & $53.4 \pm 1.1$ & $53.8 \pm 3.4$ \\
\hline
\end{tabular}

D.W.A.: dimension and weight analysis; I.A.: image analysis; I.M.: data optimization method.

the bulk neat resin (i.e. $M_{\infty}$ ) and the fiber volume fraction:

$$
\frac{M_{\infty \mathrm{r}}}{M_{\infty}}=\frac{\rho_{\mathrm{t}}}{\left(1-v_{\mathrm{f}}\right) \rho_{\mathrm{r}}}
$$

Thus, one can easily deduce the fiber volume fractions from the measured densities (i.e. $\rho_{\mathrm{t}}, \rho_{\mathrm{r}}$ ) and maximum moisture absorption capacity (i.e. $M_{\infty}, M_{\infty}$ ) of 


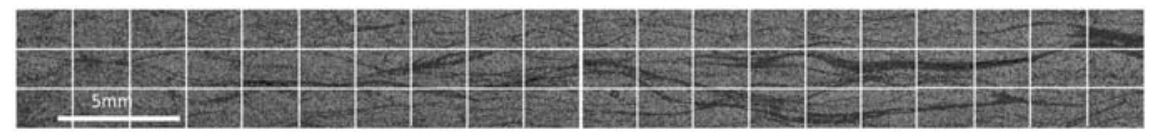

Figure I. Section of a plate with $53.4 \%$ fibers content reconstituted from 60 scanning electron microscopy (SEM) micrographs.
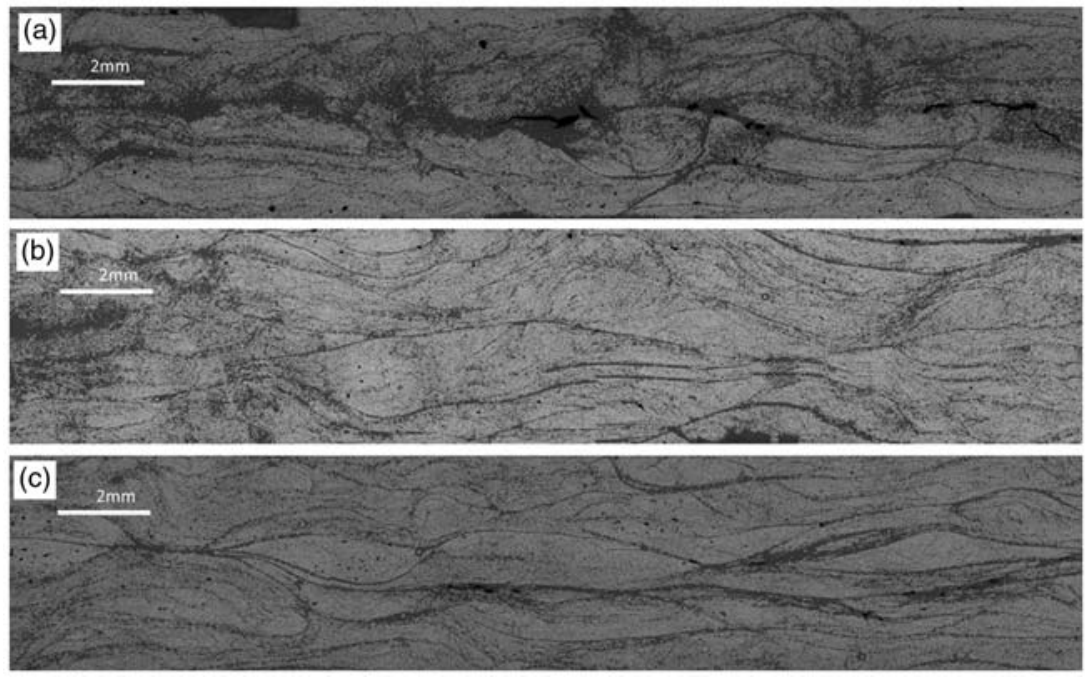

Figure 2. (a) Section of sample $N^{\circ}$ I with $41.6 \%$ fibers content. (b) Section of sample $N^{\circ} 6$ with $49.2 \%$ fibers content. (c) Section of sample $\mathrm{N} 9$ with $53.4 \%$ fibers content.

both the composite and its constitutive organic matrix, from the following relation:

$$
v_{\mathrm{f}}=1-\frac{\rho_{\mathrm{t}}}{\rho_{\mathrm{r}}} \frac{M_{\infty}}{M_{\infty}}
$$

The results obtained through this method for the fiber volume fractions of the manufactured samples are presented in Table 2 .

Review of the fiber volume fraction determination. Table 1 recapitulates the three methods used in this study, in order to compare the results.

\section{Comparisons and discussion}

According to Table 2, the fiber volume fraction varies from $35.5 \%$ to $55.6 \%$.

Numerical values provided by the three identification methods presented above are very close for most of the specimens. The discrepancy noticed on the third sample could be induced by the existence of defects in that specimen. Indeed, microstructural features such as voids or cracks have a strong influence on the maximum moisture absorption capacity and consequently, on the deduced constituents volume fraction. A structural study via an SEM is planned at the end of the aging tests for this sample, in order to investigate this phenomenon.

\section{Heterogeneity of fibers distribution}

In order to gather more information about sample microstructure and, especially on the fibers distribution homogeneity, the whole section of the plate was reconstituted from 60 SEM micrographs. Each plate section corresponds to two specimens, and each specimen is reconstituted by 30 SEM micrographs arranged in 3 lines and 10 columns. Figure 1 represents the section of one manufactured plate, with an average of $53.4 \%$ fibers content, according to the I.A. method.

According to Figure 1, the right-hand part of the plate (which corresponds to $\mathrm{N}^{\circ} 7$ sample) exhibits a less homogeneous fibers arrangement in comparison with the left part (corresponding to sample $\mathrm{N}^{\circ} 9$, respectively). This heterogeneity of the fiber distribution from one sample to another could induce a relatively different diffusive behavior of the studied specimen.

In the three specimens, fiber volume fractions vary from 41 to $53 \%$, as shown in Figure 2. Figure 2(a) shows the fiber distribution of the sample $\mathrm{N}^{\circ} 1$ and confirms that the fibers volume fraction is higher in the subsurface of the specimen than in the bulk. A stronger 

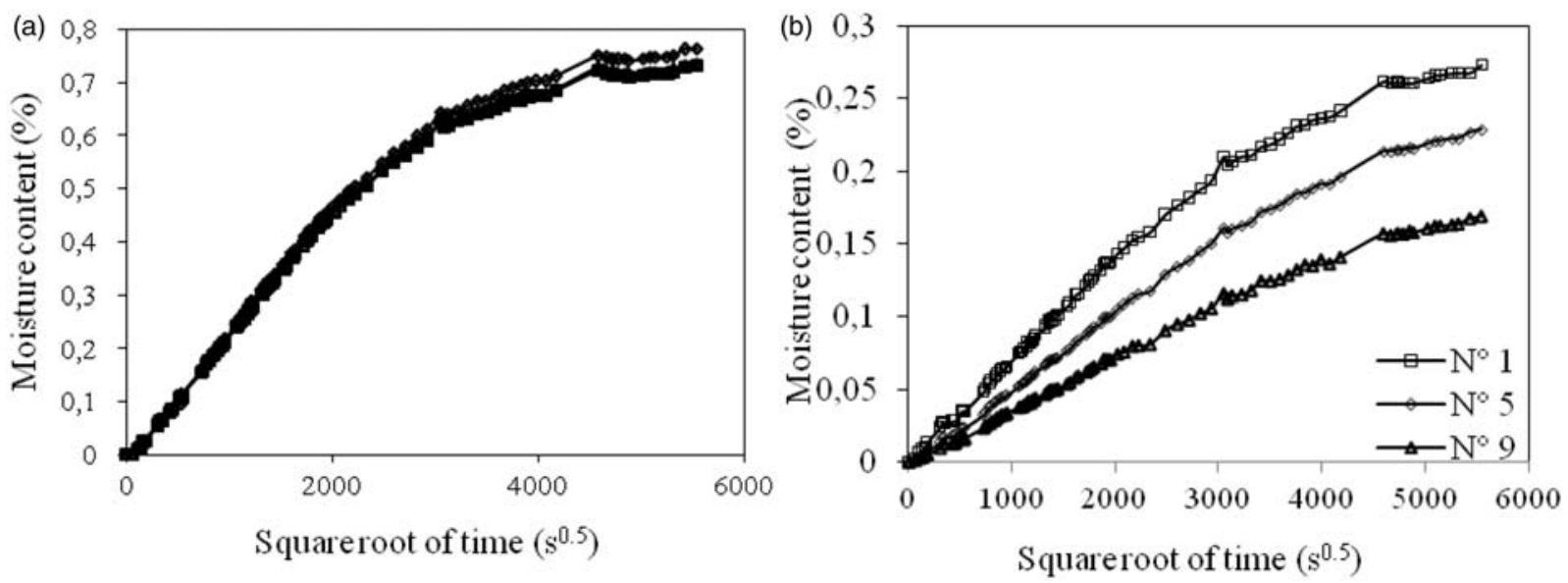

Figure 3. Moisture absorption curves for (a) resin samples and

(b) composite samples $\mathrm{N}^{\circ} \mathrm{I}, \mathrm{N}^{\circ} 5$ and $\mathrm{N}^{\circ} 9$.

heterogeneity of the in-depth reinforcements distribution is observed for sample $n^{\circ} 1$ (Figure 2(a)) compared to samples $n^{\circ} 6$ and $n^{\circ} 9$ (Figure 2(b) and (c)). Such a variation in the spatial distributions of the reinforcements results in the coexistence of resin-rich areas and reinforcements-rich areas, which present a different diffusive behavior at the local scale.

The literature indicates that the existence of such a microstructural feature could explain variations in the macroscopic effective diffusive behaviour of two composites exhibiting the same average fiber volume fractions. As an example, it was recently reported by Bao and $\mathrm{Yee}^{28}$ that heterogeneous fibers distributions, from one sample to another, were associated to a significant discrepancy between the transverse diffusion coefficients of unidirectional fiber-reinforced composites. However, the authors did not observe any effect on the maximum moisture absorption capacity.

\section{Aging and identification}

\section{Moisture absorption experiments}

The aging tests were carried out on composites and neat resin samples, in order to compare their diffusive behaviour. After cutting and polishing, the samples' surfaces were cleaned with ethanol. The initial weights of the specimens were recorded. Thereafter, specimens were immediately placed into an environmental chamber. A temperature of $23^{\circ} \mathrm{C}$ and a relative humidity of $80 \%$ were set as aging conditions. The change in mass was measured using balance with an accuracy of $0.1 \mathrm{mg}$.

The weight gain versus the square root of time $(\sqrt{t})$ curves for all composite and resins specimens were determined in order to follow their moisture absorption kinetic. Figure 3(a) represents the moisture uptake curves of three neat resin samples and Figure 3(b) represents the moisture uptake curves of the composite samples $\mathrm{N}^{\circ} 1, \mathrm{~N}^{\circ} 5$ and $\mathrm{N}^{\circ} 9$, respectively, with $41.6 \%$, $47.2 \%$ and $53.4 \%$ of fibers content. Figure 3(a) shows the good reproducibility of the moisture uptake phenomenon for the resin specimens. The neat resin actually follows a Fickian diffusion law. It can be observed in Figure 3(b) that the three composite samples exhibit an almost linear evolution of their moisture uptake for several months until a pseudo-plateau indicating that saturation of the Fickian diffusion process may be reached. It can be noted that the maximum moisture absorption capacity decreases significantly when the fiber volume fraction increases. The maximum moisture absorption capacity of the neat resin samples is at least three times more important than that of the composites ones.

\section{Identification of diffusion parameters}

According to Figure 3, an initially linear moisture uptake followed by a saturation plateau can be observed. Thus, it is realistic to consider Fickian diffusion behaviour for the investigated materials.

This behaviour is usually modeled by the relationship:

$$
\bar{\varphi}=-D \overrightarrow{\operatorname{grad}} c
$$

where $\varphi$ is the diffusive flux, $c$ is the moisture content and $D$ is the diffusion coefficient.

Fick's second law predicts the distribution of moisture as a function of time $t$ and position:

$$
\frac{\partial c}{\partial t}=\operatorname{div}(-D \overrightarrow{\operatorname{grad}} c)
$$


Table 3. Moisture diffusion parameters obtained according to different methods of identification.

\begin{tabular}{|c|c|c|c|c|c|c|}
\hline $\begin{array}{l}\mathrm{N}^{\circ} \text { of } \\
\text { specimen }\end{array}$ & $M_{(\infty)}(\%)$ (D.W.A.) & $M_{(\infty)}(\%)$ (I.A.) & $M_{(\infty)}(\%)($ (I.M.) & $\begin{array}{l}\mathrm{D} 2 * 10^{+7}\left(\mathrm{~mm}^{2} / \mathrm{s}\right) \\
\text { (D.W.A.) }\end{array}$ & $\begin{array}{l}\mathrm{D} 2 * 10^{+7} \\
\left(\mathrm{~mm}^{2} / \mathrm{s}\right)(\mathrm{I} . \mathrm{A} .)\end{array}$ & $\begin{array}{l}\mathrm{D} 2 * 10^{+7} \\
\left(\mathrm{~mm}^{2} / \mathrm{s}\right) \text { (I.M.) }\end{array}$ \\
\hline I & $0.30 \pm 0.01$ & $0.29 \pm 0.01$ & $0.28 \pm 0.01$ & $2.59 \pm 0.05$ & $2.85 \pm 0.05$ & $3.23 \pm 0.20$ \\
\hline 2 & $0.31 \pm 0.01$ & $0.30 \pm 0.01$ & $0.31 \pm 0.01$ & $2.93 \pm 0.06$ & $3.21 \pm 0.07$ & $2.93 \pm 0.22$ \\
\hline 3 & $0.31 \pm 0.02$ & $0.30 \pm 0.02$ & $0.25 \pm 0.01$ & $1.99 \pm 0.06$ & $2.22 \pm 0.07$ & $3.56 \pm 0.19$ \\
\hline 4 & $0.27 \pm 0.02$ & $0.26 \pm 0.01$ & $0.27 \pm 0.01$ & $2.05 \pm 0.04$ & $2.21 \pm 0.04$ & $2.17 \pm 0.26$ \\
\hline 5 & $0.25 \pm 0.02$ & $0.25 \pm 0.01$ & $0.27 \pm 0.02$ & $2.07 \pm 0.06$ & $2.11 \pm 0.06$ & $1.69 \pm 0.39$ \\
\hline 6 & $0.25 \pm 0.02$ & $0.24 \pm 0.01$ & $0.23 \pm 0.01$ & $1.76 \pm 0.04$ & $1.96 \pm 0.04$ & $2.22 \pm 0.22$ \\
\hline 7 & $0.21 \pm 0.01$ & $0.22 \pm 0.01$ & $0.20 \pm 0.01$ & $\mathrm{I} .8 \mathrm{I} \pm 0.04$ & $1.74 \pm 0.04$ & $2.20 \pm 0.28$ \\
\hline 8 & $0.22 \pm 0.02$ & - & $0.21 \pm 0.02$ & $1.62 \pm 0.04$ & - & $1.74 \pm 0.36$ \\
\hline 9 & $0.20 \pm 0.01$ & $0.21 \pm 0.01$ & $0.21 \pm 0.02$ & $\mathrm{I} .64 \pm 0.04$ & $\mathrm{I} .40 \pm 0.04$ & $\mathrm{I} .44 \pm 0.42$ \\
\hline
\end{tabular}

D.W.A.: dimension and weight analysis; I.A.: image analysis; I.M.: data optimization method.

For orthotropic thick plates, a 3D Fick's diffusion takes places along the axis $x, y$ and $z$ :

$$
\frac{\partial c}{\partial t}=D_{1} \frac{\partial^{2} c}{\partial x^{2}}+D_{2} \frac{\partial^{2} c}{\partial y^{2}}+D_{3} \frac{\partial^{2} c}{\partial z^{2}}
$$

where $D_{1}, D_{2}$ and $D_{3}$ are, respectively, the moisture diffusion coefficients along the axis $x, y$ and $z$.

By integrating the solution of the equation (10) over the volume of the specimens, the total moisture content $M(t)$ can be evaluated ${ }^{42}$ :

$$
\begin{aligned}
\frac{M}{M_{\infty}}= & \left.1-\left(\frac{8}{\pi^{2}}\right)^{3} \sum_{i=0}^{\infty} \sum_{j=0}^{\infty} \sum_{k=0}^{\infty} \frac{1}{((2 i+1)(2 j+1)(2 k+1))^{2}}\right) \\
& \left.\left.\times \exp -\pi^{2} t \quad D_{1}\left(\frac{2 i+1}{L}\right)^{2}+D_{2}\left(\frac{2 j+1}{l}\right)^{2}+D_{3}\left(\frac{2 k+1}{e}\right)^{2}\right)\right)
\end{aligned}
$$

where $M_{\infty}$. stands for the equilibrium moisture content, whereas $L, l$ and $e$ are, respectively, the length, the width and the thickness of the specimen.

The identification of the diffusion parameters is based on the comparison between the 3D Fick's solution and the experimental measurement of the weight gain occurring during the diffusion process. ${ }^{43}$ The method consists in seeking the unknowns of the problem by minimizing the standard deviation $q$ (equation (11)) using a Gauss-Newton algorithm. Identification method is used for several specimens at the same time.

$$
q=\sum_{i}\left[M\left(t_{i}\right)-M_{i}\right]^{2}
$$

where $M\left(t_{i}\right)$. is the analytical moisture solution at time $t_{i}$ and $M_{i}$ is the corresponding experimental point.

\section{Identification method}

\section{Simultaneous identifications}

It was shown in previous works, as an example, in Kondo and Taki, ${ }^{34}$ that the moisture diffusion coefficient of unidirectional composite in the direction parallel to the fibers was identical to the moisture diffusion coefficient of the neat resin $\left(D_{1}=D_{\mathrm{r}}\right)$. The first approach, intended for identifying both the macroscopic transverse moisture diffusion coefficient and the maximum moisture absorption capacity of the samples is based on this assumption.

The diffusivity of five neat resin specimens was identified in order to reduce the number of remaining unknown factors for the composite samples. The average of these values $\left(5.2310^{-7} \mathrm{~mm}^{2} / \mathrm{s}\right)$ was taken as the longitudinal diffusion coefficient $\left(D_{1}\right)$ for the composite samples according to the aforementioned assumption. Moreover, the average of the maximum capacity of moisture absorption for the five neat resin samples determined by this method is equal to $0.73 \%$. The transverse diffusion coefficient $\left(D_{2}\right)$ and the maximum capacity of moisture content $\left(M_{\infty}\right)$ were identified for all the composite specimens by fixing the longitudinal diffusion coefficient, this last being supposed equal to the coefficient of diffusion of the neat resin.

The $D_{2}$ and $M_{\infty}$.values identified by this method are presented in Table 3. $M_{\infty}$.was exploited in order to determine the mass and volume fraction of glass fibers of each composite sample through equation (6).

\section{Successive identifications}

An alternative method can be considered in order to determine the maximum moisture absorption capacity of the composite samples prior to identifying the 

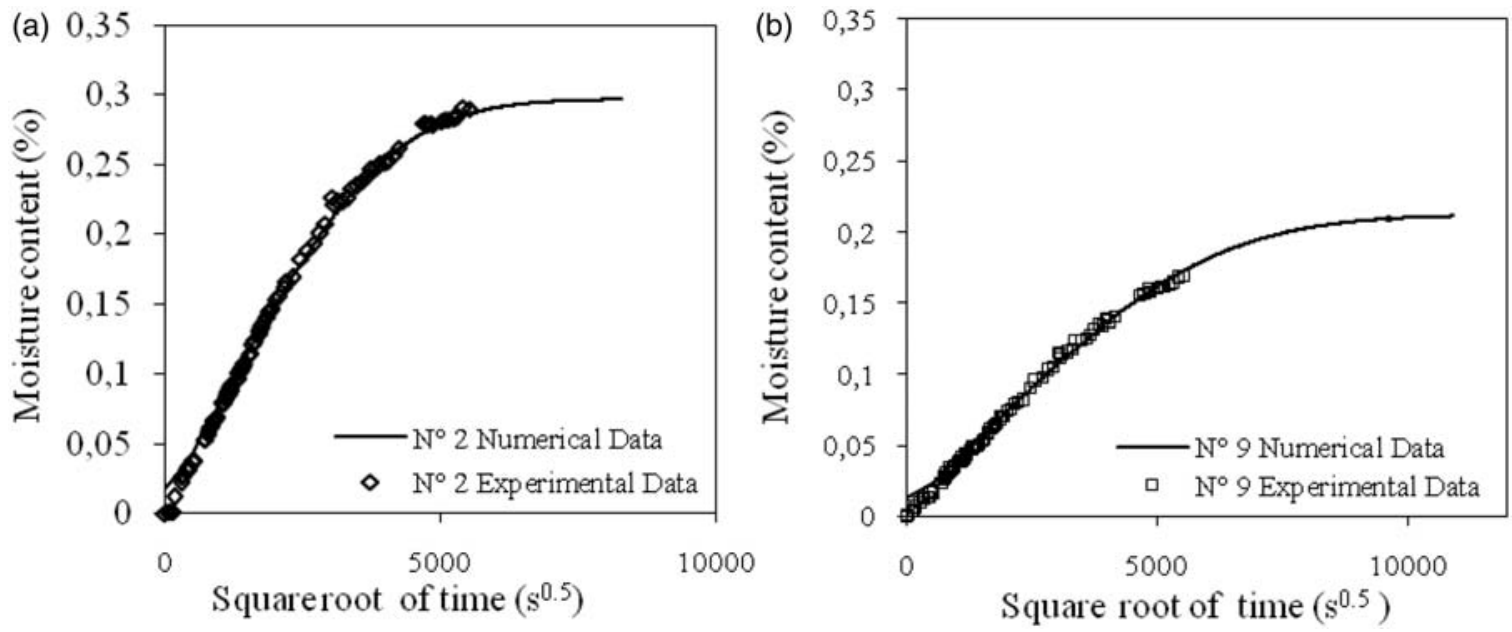

Figure 4. Experimental and numerical curves of moisture concentration for $\mathrm{N}^{\circ} 2$ and 9 composite specimens, respectively.

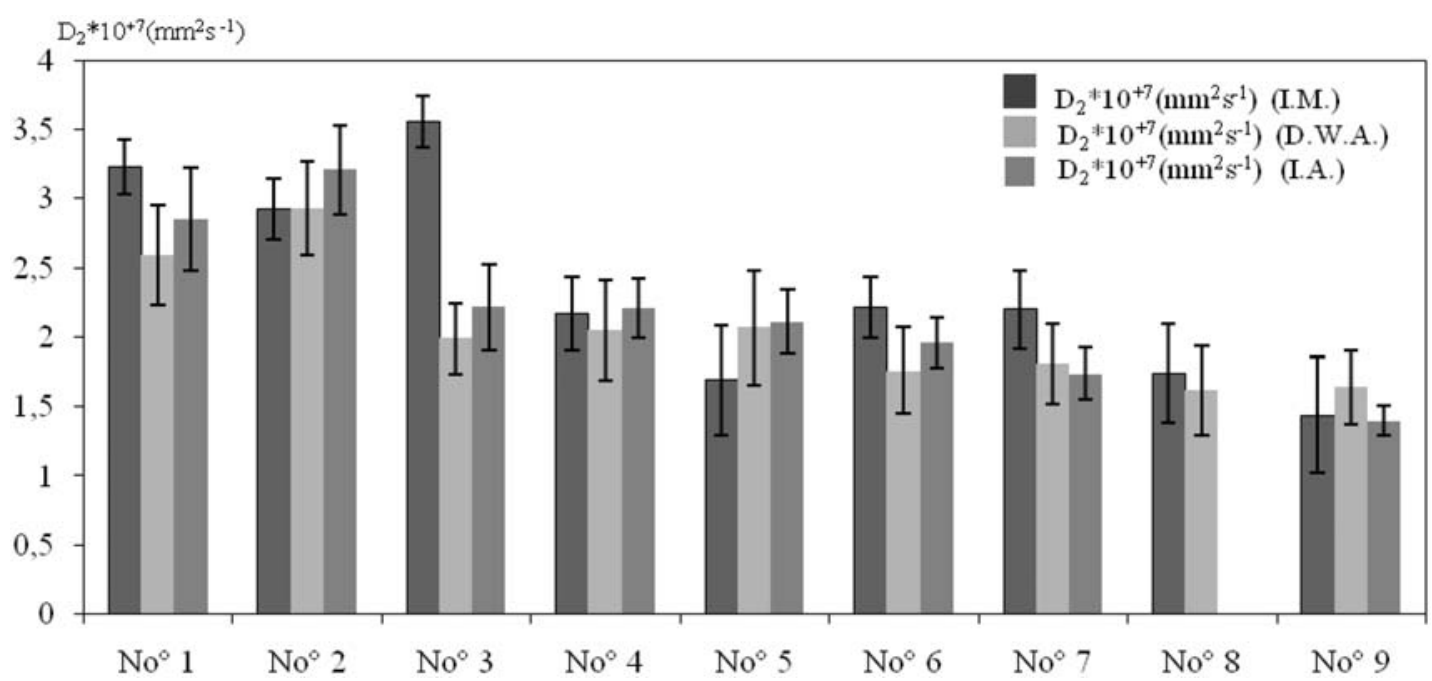

Figure 5. Comparison of the transverse diffusion coefficients identified by the different methods considered in the present work.

transverse diffusivity. Actually, Loos and Springer, ${ }^{41}$ classical relation (5) can be used in order to measure the maximum moisture absorption capacity of each manufactured composite sample, assuming that its glass-fiber volume content is known from one or another method described in experimental investigation section of the present work. After finding the maximum moisture absorption capacity of each composite specimen, its transverse moisture diffusivity can be separately identified from equation (10). Whether the so-called 'D.W.A.' or 'I.A.' method is used to find fiber volume content yields two distinct sets of numerical values for the identified diffusive behaviour law governing parameters, as shown in Table 3.
Figure 4 shows the computed evolutions obtained through the diffusive parameters adjusted according to the image analysis method, for samples $\mathrm{N}^{\circ} 2$ and $\mathrm{N}^{\circ} 9$ with $41 \%$ and $53 \%$ fiber volume content, respectively. The measured data were plotted on the same figure. This process was performed for all composite specimen and the results were analyzed.

For an enhanced comparison, the numerical values, provided in Table 3 for the transverse diffusivities, have been displayed as histograms on Figure 5. Moreover, the absolute uncertainties are noticeably lower in this case than from the so-called 'D.W.A.' or 'I.A.' data treatment methods Thus, the independent determination of the maximum moisture absorption capacity 
Table 4. Moisture diffusion parameters obtained according to different methods of identification.

\begin{tabular}{|c|c|c|c|}
\hline Method & $\begin{array}{l}\text { Hypotheses and } \\
\text { applied equation }\end{array}$ & $\begin{array}{l}\text { Identified } \\
\text { parameters }\end{array}$ & Comment \\
\hline Simultaneous identification & $\begin{array}{l}D_{2}=D_{3} \\
D_{r}=D_{1} \\
\text { (equation }(10))\end{array}$ & $D_{2} \& M_{\infty}$ & $\begin{array}{l}\text { I) The material is considered as transversely isotropic } \\
\text { 2) According to Kondo and } \mathrm{Taki}^{34} \text { the longitudinal moisture } \\
\text { diffusion coefficient of unidirectional composite is equal to } \\
\text { the moisture diffusion coefficient of the neat resin. }\end{array}$ \\
\hline Two steps identification & $\begin{array}{l}D_{2}=D_{3} \\
D_{r}=D_{1} \\
M_{\infty}=M_{\infty r} \frac{\left(1-v_{f}\right)}{\rho_{r}} \\
\text { (equation }(10))\end{array}$ & $D_{2}$ & $\begin{array}{l}\text { The fiber volume fraction of the specimens, obtained by the } \\
\text { methods D.W.A. or I.A., have respectively been used in order } \\
\text { to determine the maximum moisture absorption capacity. }\end{array}$ \\
\hline
\end{tabular}

Table 5. The various homogenization relations for the macroscopic transverse coefficient of moisture expansion, considered in the present work.

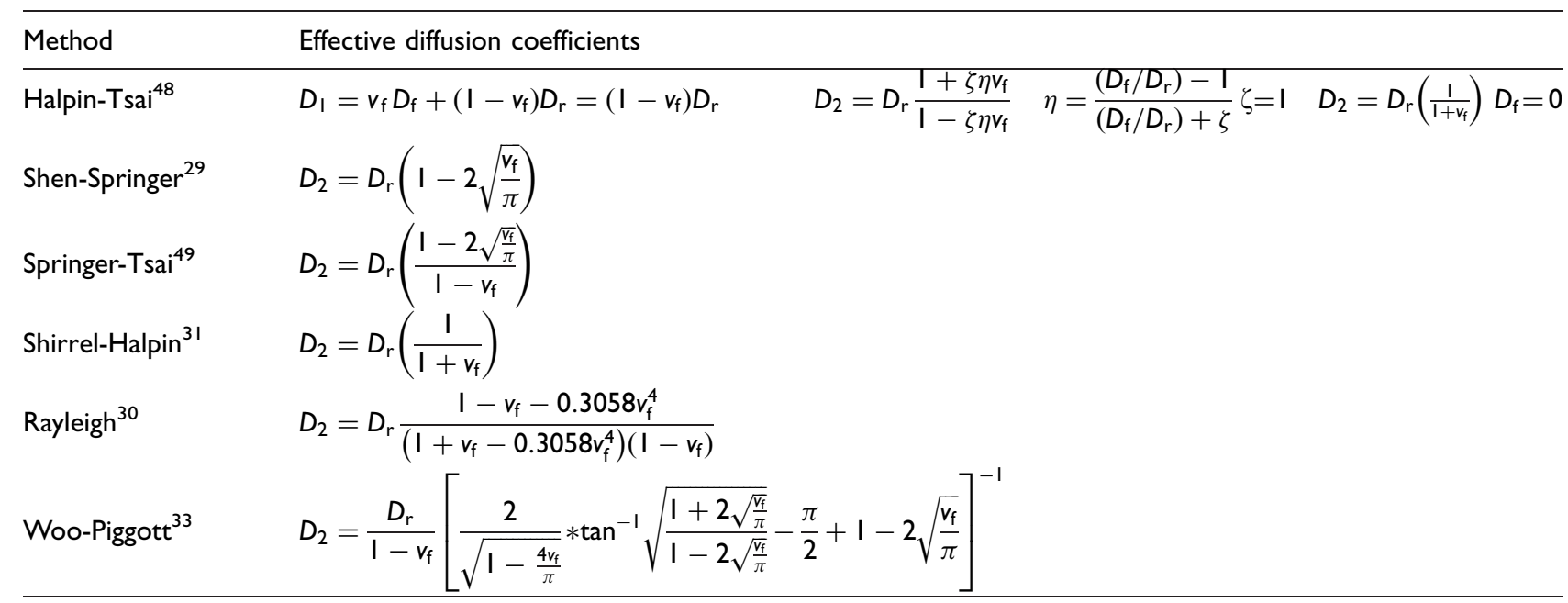

prior to the fitting of the transverse diffusion coefficient does improve the accuracy of the numerical optimization.

The agreement between the numerical results and the measured evolutions is good, whatever the considered sample. Since the composite samples did not saturate during the tests, the simulations enable to predict the maximum moisture content in the steady-state stage.

Figure 5 shows the comparison between the transverse diffusion coefficients provided by the three identification methods. Except for sample $\mathrm{N}^{\circ} 3$, the numerical values of $D_{2}$ identified on each specimen by the three methods are close.

The identification of $D_{2}$ through the so-called I.M. method deviates significantly from the values obtained according to either D.W.A. or I.A. methods, in the case that the sample $\mathrm{n}^{\circ} \mathbf{3}$ is considered. It should be reminded that, $M_{\infty}$ determined through I.M. method for this specimen was also relatively different from the values deduced from the other methods (Table 3 ).

\section{Review of the moisture diffusion parameters identification}

To understand better the different methods applied in this study, the hypotheses and equation used and also the identified parameters corresponding to each method are reminded in the Table 4.

\section{Comparison between the experimental results and the predictions of scale transition models}

Scale transition models have a long history and rich literature. Among their applications in the field of mechanical engineering, their ability to predict the effective behavior and mechanical states of 


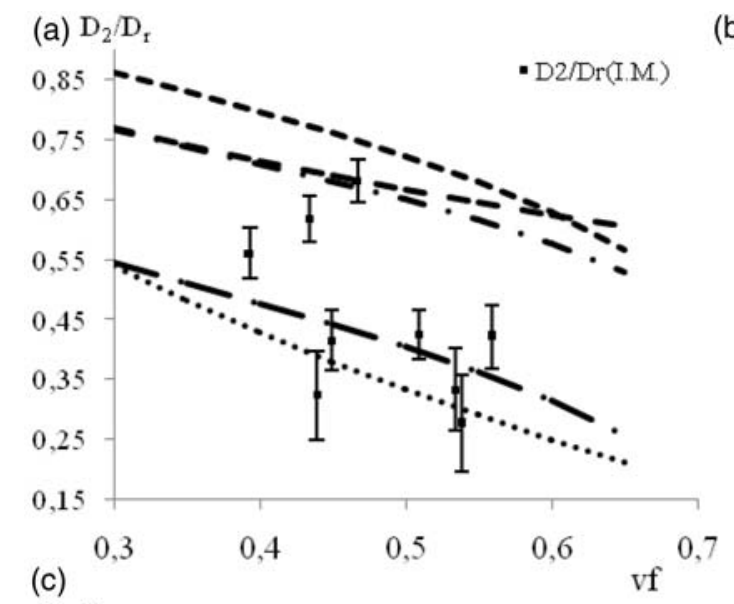

(b) $\mathrm{D}_{2} / \mathrm{D}_{\mathrm{r}}$
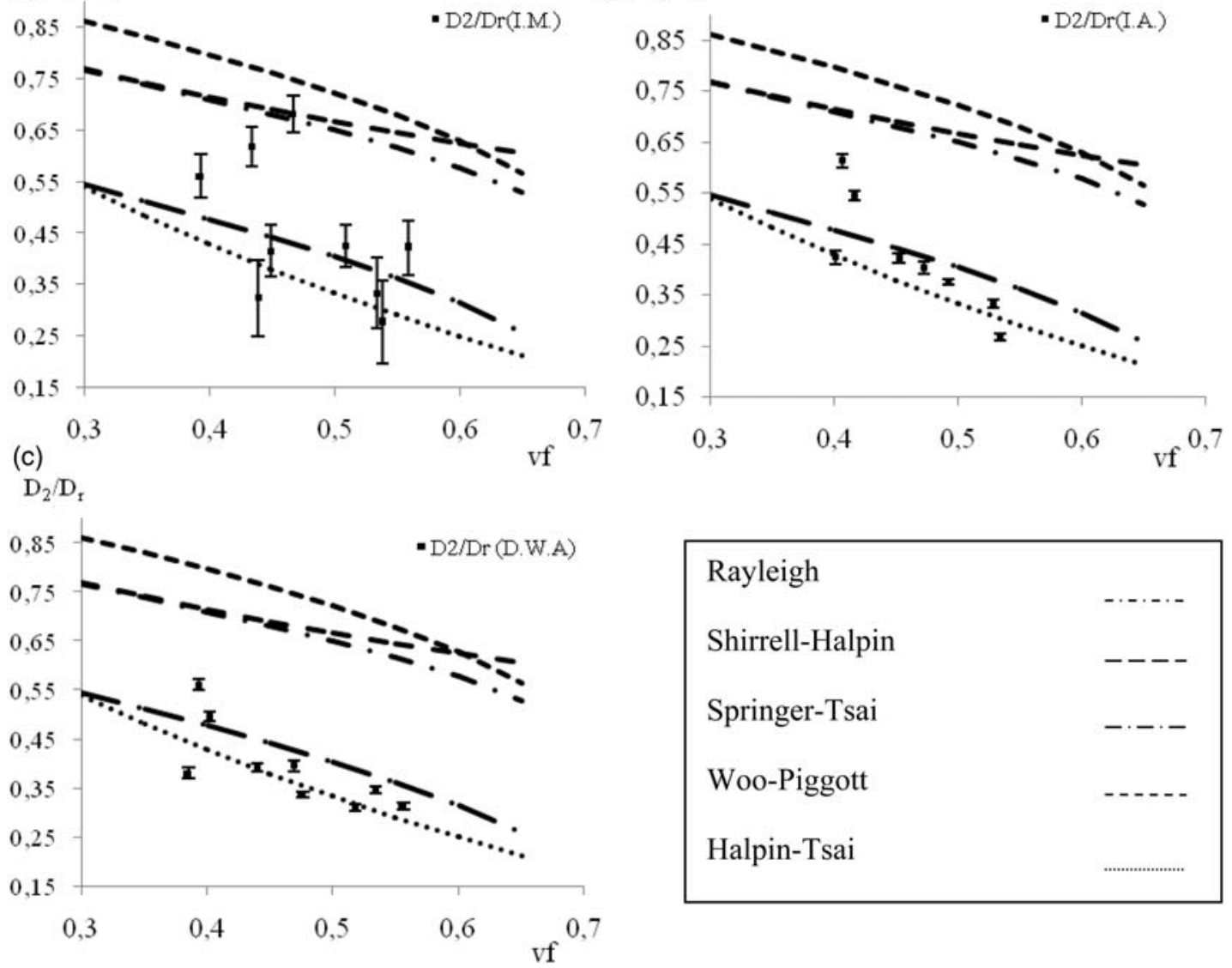

Figure 6. Comparison between the transverse diffusion coefficient identified through the three methods and the prediction provided by the scale transition models.

macroscopically homogeneous but microscopically heterogeneous materials is often valued. ${ }^{44,45}$ The connected question of predicting the macroscopic Coefficients of Thermal Expansion or the Coefficients of Moisture Expansion of such heterogeneous materials has also (in most previously cited cases) been addressed. The interested reader can refer, as an example, to Refs $[46,47]$ for recent advances in the field of micromechanical modeling about this topic. In the field of modeling the diffusion of moisture in fiber reinforced composites, various scale transition relations were proposed within historical papers, in order to handle the determination of the effective macroscopic diffusion coefficients. Some of them are already presented in the introduction of this article.

In the present work, the classical scale transition relations established by Halpin and Tsai (Halpin and Kardos ${ }^{48}$ ), Shen and Springer, ${ }^{29}$ Springer and Tsai, ${ }^{49}$ Shirell and Halpin, ${ }^{31}$ Rayleigh $^{30}$ and Woo and Piggott, ${ }^{33}$ for the effective moisture diffusion coefficient of fiber reinforced composites, are considered. The fundamental relations governing these models are summarized in Table 5.
The purpose of the present section is to compare the results deduced from our experimental investigations to the predictions of the above-listed predictive models. The transverse coefficients of moisture diffusion deduced from the practical analysis of the manufactured samples are plotted, as a function of the fiber volume fraction, as well as the corresponding quantities, and calculated through the various scale transition relations listed in Table 5. On the one hand, Figure 6(a) displays the comparison between the scale transition models and the interpretation of the experimental investigation handled through the first data optimization method (I.M.) described in Simultaneous identifications section. On the other hand, Figure 6(b) and (c) shows the corresponding curves obtained in the case that the data treatment method based on either the image analysis (I.A.) or the dimension and weight analysis (D.W.A.) was used. The values of the transverse moisture diffusion coefficient deduced from the first numerical optimization method (Figure 6(a)) is associated to relatively high uncertainties, compared to the corresponding values, plotted on Figure 6(b) and (c), obtained through the I.A. and D.W.A. based 
optimization methods. Moreover, according to Figure 6(a), the evolution of the transverse macroscopic diffusivity, as a function of the glass volume fraction deduced from the investigation achieved on the samples through the first data treatment method, is not consistent with the expected behaviour predicted by the theoretical models.

This demonstrates that the simultaneous fitting of several parameters from the classical analytical weight gain relation (10) is both inaccurate and unreliable, in spite of the fact that the deduced quantities still get a realistic value: their order of magnitude, accounting the uncertainties is correct, for a single randomly studied specimen, whereas the results obtained for the whole series of samples are unacceptably scattered.

According to Figure 6(b) and (c), the use of an alternative optimization method involving two successive steps (i.e. the independent determination of the maximum moisture absorption capacity prior to the numerical adjustment of the transverse diffusivity) corrects the issue raised above. The resulting transverse moisture coefficients are associated to very low uncertainties. Moreover, their evolution, as a function of the reinforcement volume fraction, follows the expected trend for unidirectional fiber-reinforced composites. Thus, the separate determination of the unknown main factors governing the diffusion of moisture improves the accuracy and reliability of the numerical experimental data treatment method. It is, as a consequence, strongly advised to proceed according to such a multi-step fitting procedure instead of the classical simultaneous determination of all the unknowns in a similar situation.

\section{Conclusions and perspectives}

In this study, the diffusive behaviour of a polylite 420 731 resin and of composites reinforced by unidirectional E-glass fibers was investigated. In order to reach that goal, several neat resins as well as unidirectional composite plates containing fiber volume fractions varying from $35 \%$ to $60 \%$ were manufactured through a contact molding process. Three independent characterization methods were used in order to determine the fiber volume fractions of the studied samples. They were found to provide very close values for the fiber content of one given specimen. The time-dependent moisture uptake of the samples was followed during aging in a climatic chamber by the classical gravimetric method. The moisture diffusion parameters were identified by comparison of the $3 \mathrm{D}$ analytical solution provided by $\mathrm{Crank}^{42}$ to the measured timedependent Fickian weight gain. Several data treatment methods were investigated. In the first, the maximum moisture absorption capacity and the transverse diffusion coefficient were identified simultaneously. In the other methods, it was taken into account within the analytical solution for the weight gain, the maximum moisture absorption capacity deduced from homogenization relations featuring the fiber volume fractions previously determined. This last parameter was obtained through the measurements of both the volume and the mass of the samples in the context of the second data treatment method, whereas it was determined through image analyses achieved on SEM micrographs within the third calculation scheme. The uncertainty on the fitted parameters significantly decreases with the number of materials properties simultaneously adjusted from the same analytical solution. The evolutions of the transverse diffusion coefficient predicted by traditional scale transition models were also calculated, as a function of the fiber volume fractions. Finally, a good agreement was obtained between the transverse diffusion coefficient determined from the two-steps identification method investigated in the present work, and the corresponding values predicted by either Springer-Tsai or Halpin-Tsai models.

Further similar investigations should be achieved, in order to check whether the findings concerning the realistic predictions provided by Springer-Tsai and Halpin-Tsai models for the homogenized transverse to fiber axis moisture diffusion coefficient would still be observed on other families of polymer matrix fiberreinforced composites.

\section{Funding}

This research received no specific grant from any funding agency in the public, commercial, or not-for-profit sectors.

\section{Conflict of Interest}

None declared.

\section{References}

1. Soutis C. Fibers reinforced composites in aircraft construction. Progr Aerospace Sci 2005; 41: 143-151.

2. Marsh G. FRP has advantages for light marine structures. Reinf Plast 1996; 40: 50-54.

3. Hollaway LC. The evolution of and the way forward for advanced polymer composites in the civil infrastructure. Constr Build Mater 2003; 17: 365-378.

4. Jedidi J, Jacquemin F and Vautrin A. Design of accelerated hygrothermal cycles on polymer matrix composites in the case of a supersonic aircraft. Compos Struct 2005; 68: 429-437.

5. Helbling C, Abanilla M, Lee L, et al. Issues of variability and durability under synergistic exposure conditions related to advanced polymer composites in the civil infrastructure. Compos Part A 2005; 37: 1102-1110.

6. Springer GS. (Ed) Environmental effects on composites materials, Vol. 1 . Westport, CT: Technomic Publishing Co, 1981. 
7. Selzer R and Friedrich K. Mechanical properties and failure behavior of carbon fibers-reinforced polymer composites under the influence of moisture. Compos Part A 1997; 28A: 595-604.

8. George J, Bhagawan SS and Sabu T. Effects of environment on the properties of low-density polyethylene composites reinforced with pineapple-leaf fibers. Compos $\mathrm{Sci}$ Technol 1998; 58: 1471-1485.

9. Nielsen SA and Toftegaard H. Ultrasonic measurement of elastic constants in fiber-reinforced polymer composites under influence of absorbed moisture. Ultrasonics 2000; 38: 242-246.

10. Patel BP, Ganapathi $M$ and Makhecha DP. Hygrothermal effects on the structural behaviour of thick composite laminates using higher-order theory. Compos Struct 2002; 56: 25-34.

11. Perreux D and Suri C. A study of the coupling between the phenomena of water, absorption and damage in glass/ epoxy composite pipes. Compos Sci Technol 1997; 57: 1403-1413.

12. Chiou $P$ and Bradley WL. Effects of seawater absorption on fatigue crack developments in carbon/epoxy EDT specimens. Composites 1995; 26: 869-876.

13. Weitsman YJ and Elahi M. Effects of fluids on the deformation, strength and durability of polymeric composites - An overview. Mech Time-Dependent Mater 2000; 4: 107-126.

14. Gopalan R, Rao RMVGK, Murthy MVV, et al. Diffusion studies on advanced fibers hybrid composites. $J$ Reinf Plast Compos 1986; 5: 51-61.

15. Jacquemin F and Vautrin A. A closed-form solution for the internal stresses in thick composite cylinders induced by cyclical environmental conditions. Compos Struct 2002; 58: 1-9.

16. Fréour S, Jacquemin $\mathrm{F}$ and Guillén R. On an analytical self-consistent model for internal stress prediction in fiber-reinforced composites submitted to hygroelastic load. J Reinf Plast Compos 2005; 24: 1365-1377.

17. Jacquemin F, Fréour S and Guillén R. Analytical modeling of transient hygro-elastic stress concentrationApplication to embedded optical fiber in a non-uniform transient strain field. Compos Sci Technol 2006; 66: 397-406.

18. Aboudi $\mathrm{J}$ and Williams TO. A coupled micomacromechanical analysis of hygrothermoelastic composites. Int J Solids Struct 2000; 37: 4149-4179.

19. Derrien K and Gilormini P. The effect of applied stresses on the equilibrium moisture content in polymers. Scripta Materialia 2007; 56: 297-299.

20. Derrien K and Gilormini P. The effect of moistureinduced swelling on the absorption capacity of transversely isotropic elastic polymer-matrix composites. Int $J$ Solid Struct 2009; 46: 1547-1553.

21. Youssef G, Fréour S and Jacquemin F. Stress-dependent moisture diffusion in composite materials. J Compos Mater 2009; 43(15): 1621-1637.

22. Youssef G, Fréour S and Jacquemin F. Effects of moisture dependent constituents properties on the hygroscopic stresses experienced by composite structures. Mech Compos Mater 2009; 45(4): 369-380.
23. Fahmy AA and Hurt JC. Stress dependence of water diffusion in epoxy resin. Polymer Compos 1980; 1: 77-80.

24. Marom $\mathrm{G}$ and Broutman LJ. Moisture penetration into composites under external stress. Polymer Compos 1981; 2(3): 132-136.

25. Neumann $\mathrm{S}$ and Marom G. Free-volume dependent moisture diffusion under stress in composite materials. J Mater Sci 1986; 21: 26-30.

26. Neumann $\mathrm{S}$ and Marom G. Prediction of moisture diffusion parameters in composite materials under stress. J Compos Mater 1987; 21: 68-80.

27. Yaniv $G$ and Ishai $O$. Coupling between stresses and moisture diffusion in polymeric adhesives. Polymer Eng Sci 1987; 27(10): 731-739.

28. Bao L-R and Yee AF. Moisture diffusion and hygrothermal aging in bismaleimide matrix carbon fiber composites - part I: uni-weave composites. Compos Sci Technol 2002; 62: 2099-2110.

29. Shen $\mathrm{CH}$ and Springer GS. Moisture absorption and desorption of composite materials. $J$ Compos Mater 1976; 10: 2-20.

30. Rayleigh L. On the instability of cylindrical fluid surfaces. Philosophical Magazine, Series 5 1892; 34(207): 177-180.

31. Shirell CD and Halpin J. Moisture absorption and desorption in epoxy composite laminates. In: Proceeding of the Composites Materials: Testing and Design, (Fourth Conference), ASTM STP 617 (American Society for Testing and Materials), 1977, pp. 514-528.

32. Augl JM and Berger AE. Moisture effect on carbon carbon fiber epoxy composites, In: Proceedings from the 8th SAMPE Technical Conference, Society for the Advancement of Material and Process Engineering (SAMPE), 1976, Vol. 8, pp. 383-427.

33. Woo M and Piggott MR. Water absorption of resins and composites: IV. Water transport in fiber reinforced plastics. J Compos Technol Res 1988; 10: 20-24.

34. Kondo $\mathrm{K}$ and Taki T. Moisture diffusivity of unidirectional composites. In: Springer GS (ed) Environmental Effects on Composite Materials. Vol. 2, cap.24. Lancaster: Technomic, 1984.

35. Allred RE and Hall NH. Volume fraction determination of Kevlar 49/epoxy composites. Polymer Eng Sci 1979; 19(13): 907-909.

36. Green P. Fibers volume fraction determination of carbon-epoxy composites using an acid digestion bomb. J Mater Sci Lett 1991; 10: 1162-1164.

37. Ye BS, Svenson AL and Bank LC. Mass and volume fraction properties of pultruded glass fibers-reinforced composites. Compos 1995; 26(10): 725-731.

38. Prakash R. Fibers volume fraction measurement in composites by X-ray diffractometer. Composites 1981; 12(3): 193-194.

39. Herakovitch CT. Mechanics of fibrous composites. New York: John Wiley and Sons Inc., 1998.

40. Whittenberger JD and Hurwitz FI. Determination of fibers fraction in continuous composites materials. J Mater Sci Lett 1982; 1: 249-252.

41. Loos G and Springer GS. Moisture absorption of polyester-E glass composites. J Compos Mater 1980; 14 : $142-154$. 
42. Crank J. The mathematics of Diffusion, 2nd edn. Oxford: Clarendon Press, 1975.

43. Pierron F, Poirette $Y$ and Vautrin A. A Novel procedure for identification of $3 \mathrm{D}$ moisture diffusion parameters on thick composites: theory, validation and experimental results. J Compos Mater 2002; 36(19): 2219-2243.

44. Fréour S, Jacquemin F and Guillén R. Extension of Mori-Tanaka approach to hygroelastic loading of fiberreinforced composites - Comparison with EshelbyKröner self-consistent model. $J$ Reinf Plast Compos 2006; 25: 1039-1052.

45. Lacoste E, Fréour S and Jacquemin F. On the validity of the self-consistent scale-consistent scale transition model for inclusions with varying morphologies. Mech Mater 2010; 42: 218-226.

46. Fréour S, Gloaguen D, François M, et al. Thermal properties of polycrystals - X-ray diffraction and scale transition modelling. Physica Status Solidi A 2004; 201: 59-71.

47. Jacquemin F, Fréour S and Guillén R. A hygroelastic self-consistent model for fiber-reinforced composites. $J$ Reinf Plast Compos 2005; 24: 485-502.

48. Halpin JC and Kardos JL. The Halpin-Tsai equations: A review. Polym Eng Sci 1976; 16: 344-352.

49. Springer GS and Tsai SW. Thermal conductivities of undirectional materials. J Compos Mater 1967; 1: 166-173. 